\title{
Histone deacetylase-4 is required during early cranial neural crest development for generation of the zebrafish palatal skeleton
}

\author{
April DeLaurier ${ }^{1 *}$, Yukio Nakamura ${ }^{2}$ Ingo Braasch', Vishesh Khanna ${ }^{1}$, Hiroyuki Kato ${ }^{3}$, Shigeyuki Wakitani ${ }^{4}$,
} John H Postlethwait ${ }^{1}$ and Charles B Kimmel ${ }^{1}$

\begin{abstract}
Background: Histone deacetylase-4 (Hdac4) is a class II histone deacetylase that inhibits the activity of transcription factors. In humans, HDAC4 deficiency is associated with non-syndromic oral clefts and brachydactyly mental retardation syndrome (BDMR) with craniofacial abnormalities.

Results: We identify hdac4 in zebrafish and characterize its function in craniofacial morphogenesis. The gene is present as a single copy, and the deduced Hdac4 protein sequence shares all known functional domains with human HDAC4. The zebrafish hdac4 transcript is widely present in migratory cranial neural crest (CNC) cells of the embryo, including populations migrating around the eye, which previously have been shown to contribute to the formation of the palatal skeleton of the early larva. Embryos injected with hdac4 morpholinos (MO) have reduced or absent CNC populations that normally migrate medial to the eye. CNC-derived palatal precursor cells do not recover at the post-migratory stage, and subsequently we found that defects in the developing cartilaginous palatal skeleton correlate with reduction or absence of early CNC cells. Palatal skeletal defects prominently include a shortened, clefted, or missing ethmoid plate, and are associated with a shortening of the face of young larvae.

Conclusions: Our results demonstrate that Hdac4 is a regulator of CNC-derived palatal skeletal precursors during early embryogenesis. Cleft palate resulting from HDAC4 mutations in human patients may result from defects in a homologous CNC progenitor cell population.
\end{abstract}

Keywords: Cartilage, hdac4, Neural crest, Palate, Skeleton, Zebrafish

\section{Background}

The vertebrate craniofacial skeleton is comprised of a complex array of cartilaginous and bony elements that must develop properly to enable efficient respiration, vocalization, and feeding. Skeletal structures of the face are derived from cranial neural crest $(\mathrm{CNC})$ cells that develop at the interface of the presumptive epidermis and the neural tube, and migrate to form the pharyngeal arches, establishing progenitor populations of skeletogenic cells in the head $[1,2]$. Disruption of CNC cell behavior, or defects in $\mathrm{CNC}$-derived tissue patterning, as might arise when function of a developmental regulatory

\footnotetext{
*Correspondence: april@uoneuro.uoregon.edu

'Institute of Neuroscience, 1254 University of Oregon, Eugene, OR 97403, USA Full list of author information is available at the end of the article
}

gene is lost, can result in craniofacial disorders such as cleft palate, one of the most common birth defects in humans $[3,4]$. Here we examine function of a gene important for palatogenesis, hdac4.

Hdac4 is a class II histone deacetylase that by binds to other HDACs and myocyte enhancing factor-2 (Mef2) to inhibit transcription factor binding to target DNA [5-8]. In humans, single-nucleotide polymorphisms (SNPs) in HDAC4 are associated with non-syndromic oral clefts [9], and haploinsufficiency of HDAC4 causes brachydactyly mental retardation syndrome (BDMR) [OMIM: 600430] with associated craniofacial abnormalities [10]. The mechanism by which loss of HDAC4 causes cleft palatal disorder in humans is unknown. In mice, Hdac4 is expressed in a number of cell types including chondrocytes, and has a critical role in regulating endochondral

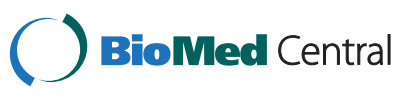


ossification [11]. Establishing the function of Hdac4 in craniofacial development is critical for understanding how disruption of this gene causes craniofacial skeletal defects.

Zebrafish provide a useful model for learning about craniofacial development, including understanding of the mechanisms of morphogenesis and genetic pathways that regulate the very early stages of palatogenesis [12-14]. It has been previously shown that CNC-derived palatal precursor cells migrate both rostrally and caudally to the eye to condense on the oral ectoderm, forming the palate in both mammals and zebrafish $[12,13,15,16]$. In both zebrafish and mammals, the palatal skeleton initiates as paired trabeculae cranii of the cartilaginous neurocranium $[17,18]$. Whereas mammals undergo extensive morphogenesis of the palate, including maxillary shelf formation and elevation, zebrafish eventually develop a more simplified palate, without shelves. Functionally, the anterior neurocranium of the early larva zebrafish supports the roof of the mouth, and hence is similar in function to the palate in mammals.

We recently reported that a prominent clefting of the zebrafish palatal skeleton results from loss of function mutation of platelet-derived growth factor receptor-a (pdgfra), and over-expression of the microRNA miR-140, which regulates the function of pdgfra [14]. Disruption of both genes also results in cleft palatal defects in mice or humans [19-21] demonstrating a shared genetic basis to palate formation among these species. Particularly relevant to the hdac4 analyses we report here, clefting of the zebrafish palatal skeleton with loss of Pdgf signaling is due to a very early cellular defect. This defect involves a failure of a subset of CNC cells, those that normally generate the medial ethmoid plate, to disperse and migrate properly to reach the oral ectoderm where they condense [14].

In the present study we show that hdac4 is required in this same Pdgfra-dependent population of CNC cells for the generation of anterior facial structures in zebrafish. Transcripts of hdac4 are expressed in premigratory and migrating $\mathrm{CNC}$ cells. Morpholino mediated knockdown of hdac4 results in an absence of anterior CNC-derived precursor cells that normally migrate medial to the eye to generate the ethmoid plate. An absence of postmigratory $\mathrm{CNC}$ cells along an anterior portion of oral ectoderm is subsequently associated with a shortened, clefted, or missing ethmoid plate cartilage of the palatal skeleton. Since defects in HDAC4 in humans have been associated with mid-facial deformities, including cleft palate, understanding the function of Hdac4 in zebrafish may offer essential insights into understanding the mechanism by which this gene may normally function in the specification and/or migration of CNC cells in the development of the vertebrate face.

\section{Results}

Identification of hdac4 in zebrafish and mRNA expression in the developing head

BLAST searches of the zebrafish genome with the human HDAC4 protein sequence returned a single closely related sequence on chromosome 9 with conservation of HDAC4 functional domains (Figure 1A, Additional file 1: Figure S1) [22-24]. Phylogenetic and syntenic analyses of the single zebrafish hdac4 gene showed that it is orthologous to one of the duplicated hdac4 sequences, hdac4a, present in several other teleosts, and orthologous to human HDAC4 (Additional file 2: Figure S2, Additional file 3: Figure S3). Analysis with Microinspector [25] of the complete sequence of hdac4 identifies two potential targets for the microRNA miR-140: one target inside exon-3, and another target spanning the end of exon-11 and beginning of exon-12 (data not shown), of interest because of previous work showing a role of this microRNA in palatal patterning [14].

RT-PCR of whole embryos revealed mRNA expression of hdac4 as early as $4 \mathrm{hpf}$, continuing until at least 6 dpf (data not shown). Whole-mount mRNA in situ hybridization showed hdac4 expression in the head at $15 \mathrm{hpf}$ (hours post-fertilization) (Figure 1B). In particular, hdac4 expression appeared strong in regions posterior and dorsal to the forming eye (Figure 1B), closely matching expression of pdgfra, a marker of migrating CNC cells (Figure 1C). The overlapping expression of hdac4 and pdgfra (Figure 1D) suggests that hdac4 is expressed in migrating CNC. At $17 \mathrm{hpf}$, the overlap of expression between hdac4 and pdgfra was more apparent (Figure 1E-G), with expression of both genes dorsal to the eye, medial to the eye, and posterior to the eye. mRNA transcript of hdac4 is broadly expressed throughout the head after $17 \mathrm{hpf}$, until about $72 \mathrm{hpf}$, when expression becomes localized to sox9-expressing cartilages in the pharyngeal arches (Figure $1 \mathrm{H}, \mathrm{J}$ arrows), mesenchyme surrounding the cartilages, and the pectoral fin (Figure 1H). At this same stage, hdac4 is also expressed in the trabeculae and ethmoid plate (Figure $1 \mathrm{~K}-\mathrm{M}$ ).

\section{MO-knockdown of hdac4 results in facial shortening and loss of palatal cartilage}

Co-injection of splice-blocking morpholinos, MO1 and MO2 (Figure 2A, see Methods, hereafter referred to as 'MO-injection'), resulted in more complete protein knockdown than either MO alone (Figure 2B). At $24 \mathrm{hpf}$, almost no Hdac4 protein was detected in MO-injected embryos compared with uninjected controls (Figure 2B). By $6 \mathrm{dpf}$ (days post-fertilization), protein loss was still apparent, although some expression was detected in $\mathrm{MO}$ injected larvae (Figure 2B). MO-injected embryos and larvae had a distinctive facial shortening compared with uninjected controls (Figure 2C-F, red arrows in C and D). 


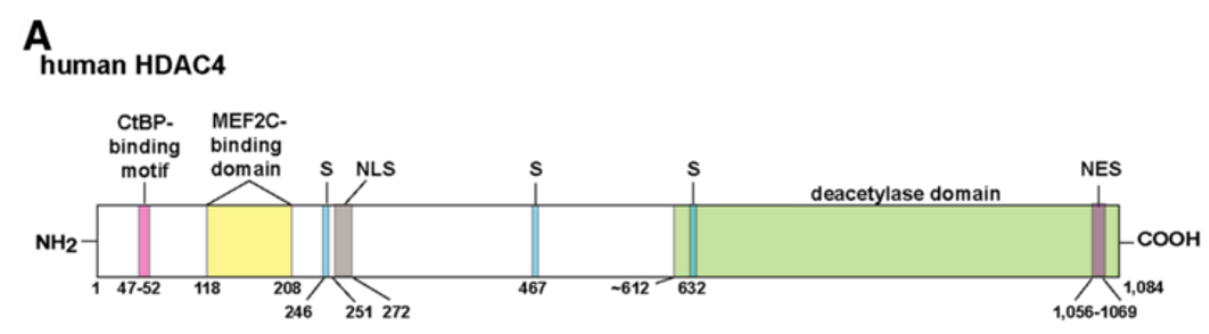

zebrafish Hdac4
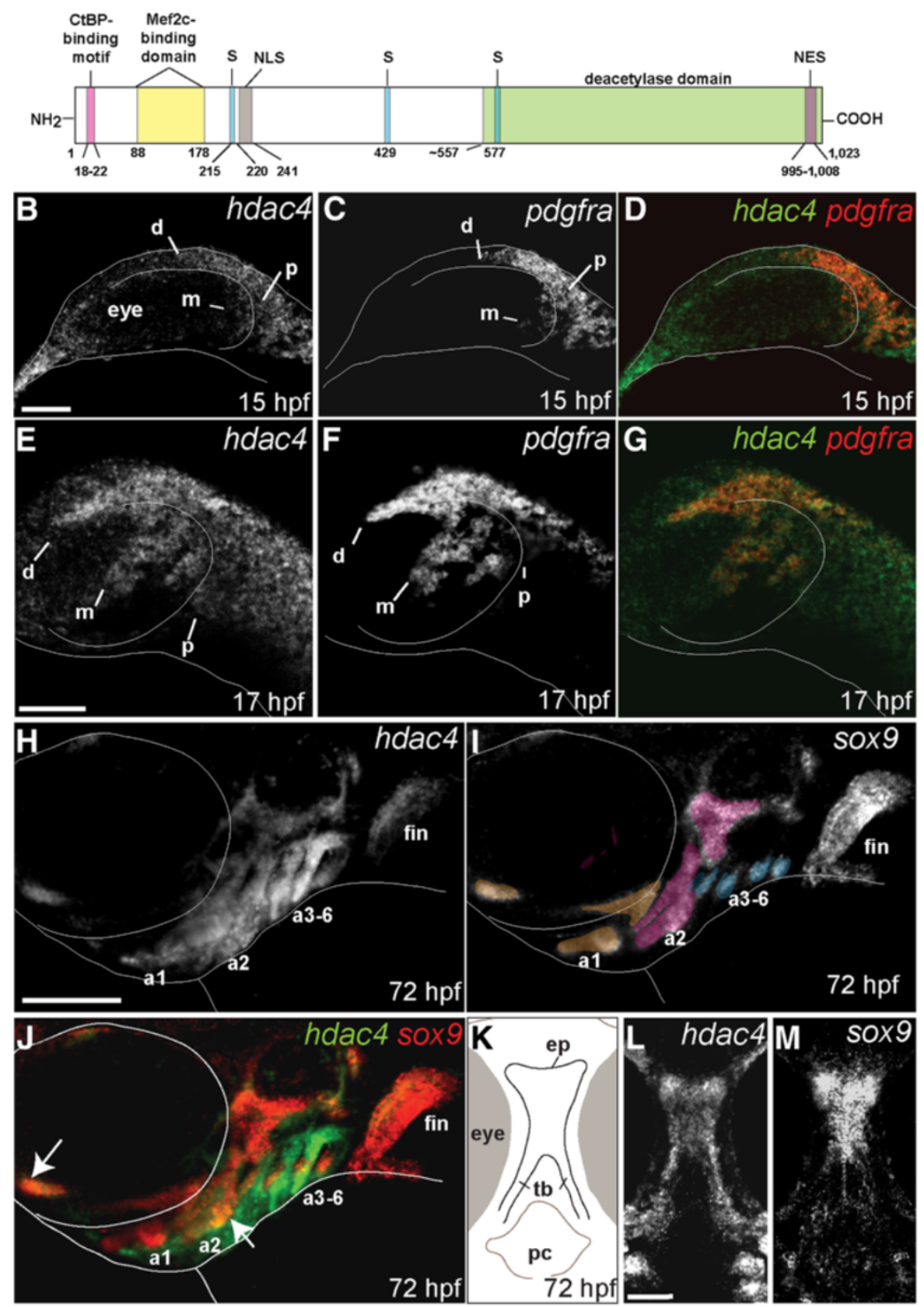

Figure 1 (See legend on next page.) 
(See figure on previous page.)

Figure 1 Identification of zebrafish Hdac4 and characterization of mRNA expression in the developing head. (A) Zebrafish Hdac4 protein contains functional domains conserved with human HDAC4, including nuclear localization (NLS), nuclear export (NES), and phosphorylation (S) sites [22-24,26]. (B-J) mRNA in situ hybridizations, anterior is to the left, dorsal is up. Images are projections from confocal stacks taken from the left side of the embryo. ( $\mathbf{L}$ and $\mathbf{M}$ ) Images are projections from confocal stacks of dissected flat-mounts, ventral side facing upwards. (B) hdac4 mRNA is expressed throughout the head at 15 hpf, with expression posterior (p) and dorsal (d) to the eye. Transcript for hdac4 is also expressed medial to the eye (m). (C) pdgfra mRNA expression at 15 hpf, posterior to the eye (p), dorsal to the eye (d), and medial to the eye (m). (D) hdac4 and pdgfra are co-expressed at 15 hpf. (E-G) hdac4 and pdgfra mRNAs are co-expressed at $17 \mathrm{hpf}$ in three streams of expression, including dorsal to the eye (d), posterior to the eye (p), and medial to the eye (m). (H) At 72 hpf, hdac4 mRNA is expressed throughout the pharyngeal arches (a1, a2, a3-6) and the pectoral fin. (I) sox9 mRNA is expressed in developing cartilage (arch 1 (a1) derivatives pseudocolored in tan, arch 2 (a2) magenta, and arches 3-6 (a3-6) blue). ( $\mathbf{J}$ ) hdac4 mRNA is co-expressed with sox9 in some regions of arch 1 and 2 cartilages (indicated by white arrows), but primarily surrounds sox9-expressing chondrocytes in arches 3-6. (K) Schematic of ventral view of dissected embryo at $72 \mathrm{hpf}$ showing the ethmoid plate (ep) and trabeculae (tb) of the palatal skeleton, and pharyngeal cavity (pc). (L and $\mathbf{M})$ hdac4 mRNA is expressed in the ethmoid plate and trabeculae of the palatal skeleton. (M) sox9 is expressed in the ethmoid plate. $\mathbf{B}-\mathbf{G}$ : scale bar $=50 \mu m, \mathbf{H}-J$ : scale bar $=200 \mu \mathrm{m}, \mathbf{L}$ and $\mathbf{M}$ : scale bar $=50 \mu \mathrm{m}$.

Skeletal preparations showed variable defects in palatal cartilage, predominantly including a shortening, narrowing, and loss of cartilage in the ethmoid plate or trabeculae communis (Figure 2H-K). Other palatal defects ranged from notches and holes in the ethmoid plate (Figure $2 \mathrm{H}$ and $\mathrm{I}$ ), shortening of the trabeculae and ethmoid plate (Figure $2 \mathrm{H}-\mathrm{J})$, to clefting of the palatal skeleton (Figure 2J and K). In contrast, the parachordal cartilage of the posterior neurocranium was relatively unaffected (Figure 1G). Injection of a third spliceblocking $\mathrm{MO}$ or a translation-blocking $\mathrm{MO}$ generated a spectrum of palatal skeletal defects comparable with

A

B
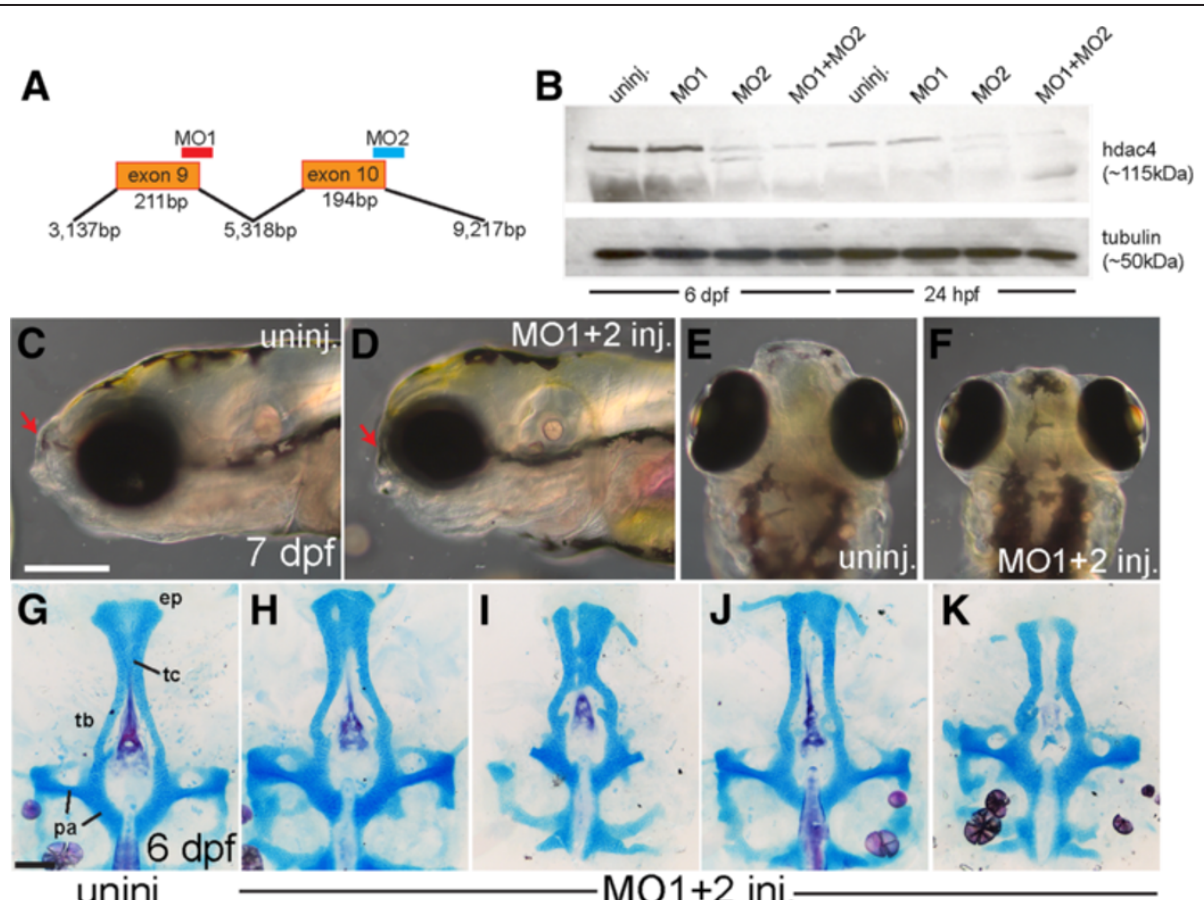

H I
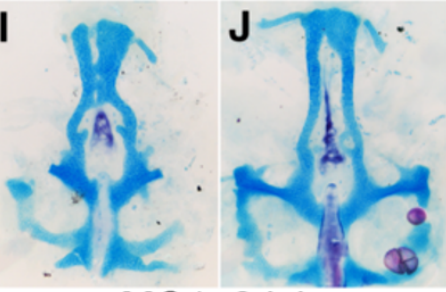

$\mathbf{K}$

Figure 2 Morpholino-knockdown of hdac4 results in facial shortening and defects in palatal skeleton cartilage. (A) Splice-blocking morpholinos MO1 and MO2 target exon-9 and exon-10 of hdac4 mRNA. (B) Western blot shows down-regulation of Hdac4 protein in extracts of MO-injected embryos and larvae at $24 \mathrm{hpf}$ and $6 \mathrm{dpf}$. Co-injection of MO1 $(12 \mathrm{mg} / \mathrm{ml})+\mathrm{MO} 2(2 \mathrm{mg} / \mathrm{ml})$ showed greater down-regulation of protein levels than injection of either $\mathbf{M O}$ alone. (C-F) Whole-mount images of living embryos at $\mathbf{7} \mathbf{d p f}$. $\mathbf{C}$ and $\mathbf{D}$ are lateral views with anterior towards the left and dorsal upwards, E and F are dorsal views with anterior upwards and dorsal is facing. (C and E) In uninjected fish, the face projects anterior to the eyes (indicated by red arrow in $\mathbf{C}$ ). ( $\mathbf{D}$ and $\mathbf{E}$ ) The anterior projection of the face is lacking in MO-injected fish (indicated by red arrows in $\mathbf{C}$ and $\mathbf{D})$. (G-K) Ventral view of Alcian Blue (cartilage) and Alizarin Red (bone) stained palatal skeletons, flat-mounted at $6 \mathrm{dpf}$. Anterior is upwards. (G) Uninjected fish have a normal palatal skeleton with trabeculae (tb), an ethmoid plate (ep), trabeculae communis (tc), and parachordal cartilage (pa). (H-J) MO-injected fish have a variety of palatal skeletal defects including shortened or narrowing of the ethmoid plate $(\mathbf{H}-\mathbf{K})$, holes in the ethmoid plate $(\mathbf{H})$, clefts $(\mathbf{I}$ and $\mathbf{K})$, and weak or absent trabeculae communii $(\mathbf{H}-\mathbf{K})$. C-F: scale bar $=250 \mu \mathrm{m}$, G-K: scale bar $=100 \mu \mathrm{m}$ 
MO1 and MO2 injections (data not shown). Injection of MO targeting hdac4 also resulted in cartilage and bone defects in the pharyngeal arches, which we are currently examining, and which may be unrelated to the palatal defects. Pharyngeal arch defects in MO-injected larvae include a gap in the hyosymplectic cartilage, and a sticklike opercle bone, which normally forms a fan-like shape (data not shown).

\section{Over-expression of hdac4 mRNA rescues palatal skeleton defects associated with MO-injection and causes severe midline craniofacial defects}

Injection of hdac4 mRNA results in a phenotype in which midline patterning of the skeleton is impaired (Figure 3A, B). This skeletal phenotype is accompanied by cyclopia. The palatal skeleton is reduced to a single cartilage rod present in the midline (Figure 3C, D). This palatal defect, as well as cyclopia, in injected larvae matches the phenotypes of midline patterning mutants that act during or shortly after gastrulation $[27,28]$, hence suggesting that hdac4 over-expression is also affecting patterning at the same very early stages.
Embryos were co-injected with hdac4 mRNA and MOs to attempt rescue of the hdac4 MO phenotype, and test the MO specificity. Injection of hdac4 mRNA along with hdac4 MO resulted in Hdac4 protein levels at $24 \mathrm{hpf}$ that were similar to levels detected in uninjected embryos - less than mRNA injection alone, and more than MO-injection alone (Figure 3E). Apparent differences in levels of Hdac4 protein expression in MOinjected embryos compared with uninjected embryos (Figure $3 \mathrm{E}$ vs. Figure 2B) are due to the inherent variability between Western blots performed on different days. Therefore, comparisons should be made within, not between these experiments.

In $6 \mathrm{dpf}$ larvae, we still observed the spectrum of palatal skeletal defects characteristic of MO-only injection (as in Figure $2 \mathrm{H}-\mathrm{K}$ ), but these defects occurred at lower incidence as compared with MO-only injection $(5 / 41=12 \%$ versus $40 / 118=34 \%$; Figure $3 \mathrm{~F})$, suggesting that we obtained partial rescue of the MO phenotype. Co-injection of hdac4 splice-blocking MO with mRNA had no effect on the incidence of the over-expression phenotype induced by the full-length mRNA (10/ $50=20 \%$ versus $8 / 41=20 \%$ ). This finding was expected

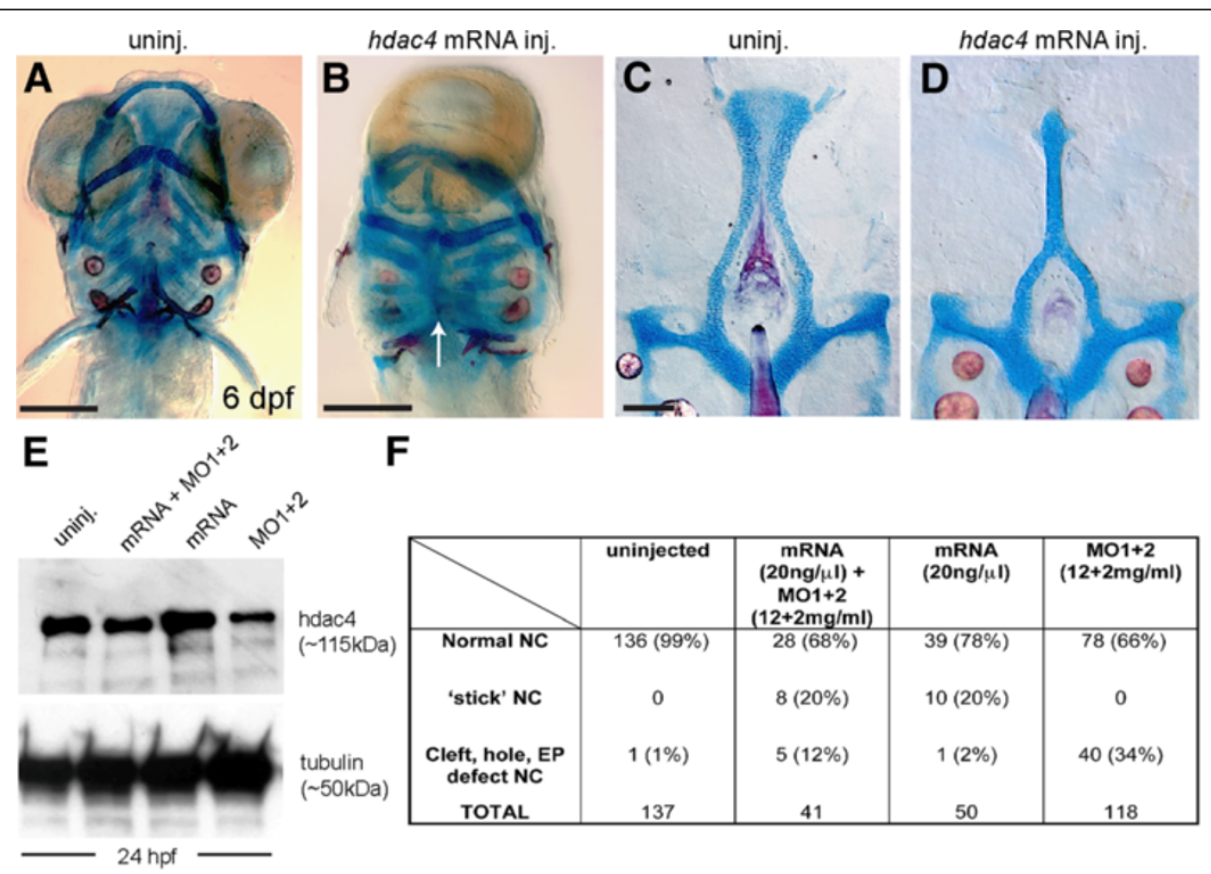

Figure 3 Over-expression of hdac4 mRNA rescues palatal defects associated with MO-injection and causes midline craniofacial defects. (A-D) Alcian Blue (cartilage) and Alizarin Red (bone) stained embryos and dissected palatal skeletons. (A and B) Ventral view of whole-mount skeletal preparations of $6 \mathrm{dpf}$ larvae, anterior is upwards, ventral is facing. (C and D) Flat-mounts of palatal skeletons at 6 dpf. Anterior is upwards. (A) Uninjected fish have normal development of craniofacial cartilage and bone. (B) hdac4 mRNA injection resulted in cyclopia and a loss of normal midline patterning (indicated by white arrow). (C) Uninjected fish have normal palatal skeletons. (D) hdac4 mRNA injection results in 'stick'-like palatal skeletons. (E) Co-injection of hdac4 mRNA $(20 \mathrm{ng} / \mathrm{\mu l})$ and $\mathrm{MO} 1+2(12+2 \mathrm{mg} / \mathrm{ml})$ resulted in protein levels similar to levels in uninjected embryos 24 hours post-injection, compared with injection of mRNA or MOs alone. (F) Embryos used for the protein assay were also raised to $6 \mathrm{dpf}$ and scored for palatal phenotypes. Co-injection of hdac4 mRNA with MO1 + 2 resulted in a decrease of MO-like defects (i.e. cleft, hole, ethmoid plate (EP) defects) compared with MO-injection alone. $\mathbf{A}$ and $\mathbf{B}$, scale bar $=200 \mu \mathrm{m}$; $\mathbf{C}$ and $\mathbf{D}$, scale bar $=100 \mu \mathrm{m}$. 
since the splice-blocking MO would have no effect on spliced mRNA.

\section{A migratory cranial neural crest cell population medial to the eye is severely reduced in hdac4 MO-injected embryos}

The palatal skeletal defects resulting from hdac4 MOinjection are similar to the defects observed in pdgrfra mutants [14]. In the pdgfra mutant, development of the palatal skeleton is disrupted due to a defect of migration of a subset of CNC cells [14]. Resemblance of the hdac4 palatal skeletal phenotype with that of the pdgfra mutant motivates the hypothesis that loss of hdac4 also results in disruption of CNC migration. To test this hypothesis, we first examined expression of pdgfra itself, an excellent marker of the early CNC $[14,20,29]$. We observed that at the stage of migration, at $15 \mathrm{hpf}$, pdgfra expression appeared diminished in MO-injected embryos in a small region where cells normally are migrating medial to the eye (Figure 4A, B). This reduction was specific, for we did not detect differences in pdgfra expression dorsal or posterior to the eye (Figure 4A, B). In contrast,

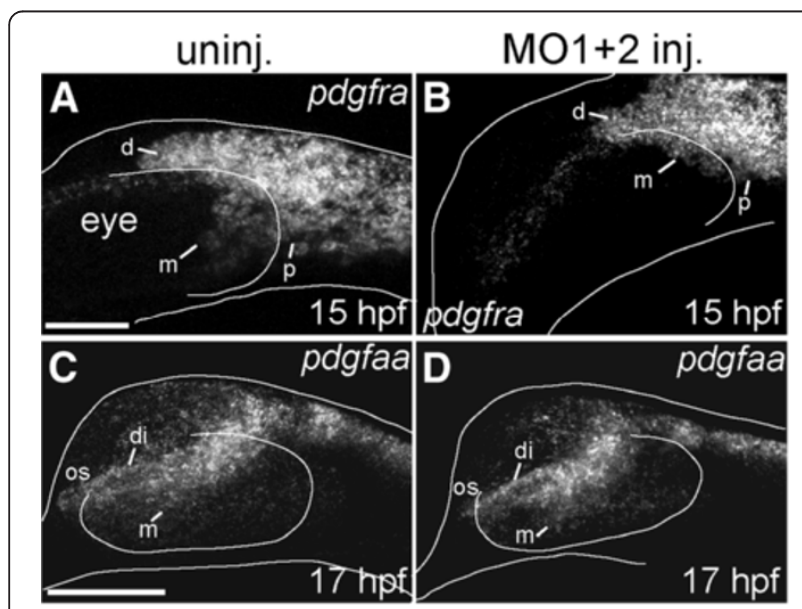

Figure 4 pdgfra mRNA expression is down-regulated in hdac4 MO-injected embryos, although the ligand pdgfaa is unaffected. (A-D) mRNA in situ hybridizations, lateral views where anterior is towards the left, dorsal is upwards, Images are projections from confocal stacks. Dorsal and ventral margins and the eye margin of the embryo were outlined from brightfield images. (A) Uninjected embryos showed expression of pdgfra dorsal to the eye (d), posterior to the eye (p), and medial to the eye (m) at $15 \mathrm{hpf}$. (B) MO-injected embryos showed more limited expression of pdgfra, in particular loss of pdgfra expression medial to the eye $(\mathrm{m})$ at $15 \mathrm{hpf}$ (compare $\mathrm{m}$ in $\mathbf{A}$ with B). (C) At $17 \mathrm{hpf}$, uninjected embryos showed pdgfaa mRNA expression in the diencephalon (di), medial to the eye $(\mathrm{m})$, and in the optic stalk anterior to the eye (os). (D) At $17 \mathrm{hpf}$, hdac4 MO-injected embryos had similar patterns of pdgfaa mRNA expression in the diencephalon (di), medial to the eye $(\mathrm{m})$, and in the optic stalk (OS). A and B, scale bar $=50 \mu \mathrm{m}$, C-D scale bar $=100 \mu \mathrm{m}$ when migration is normally just beginning at 12 and 14 hpf, we observed no differences in pdgfra expression between MO-injected embryos and uninjected controls, (data not shown). Expression of the ligand pdgfaa at 15 hpf (data not shown) and 17 hpf (Figure 4C, D) appeared normal in the optic-stalk of MO-injected embryos, suggesting that the ligand for pdgfra-expressing CNC cells is not lost with knockdown of hdac4 [14]. Seemingly normal $p d g f a a$ expression in MO-injected embryos suggests that at least one key feature of the environment into which $\mathrm{CNC}$ cells migrate may not be affected by knockdown of hdac4, and furthermore that the defect originates within the specific population of $\mathrm{CNC}$ cells that migrate medial to the eye.

Sonic hedgehog $(s h h)$ is another factor necessary for establishing the environment for palatogenesis in zebrafish [12,13]. mRNA expression of shh was not altered in hdac4-MO injected embryos, at 10 and $14 \mathrm{hpf}$, when cells are migrating from the progenitor pool, and at 36 hpf, when cells are at the antero-ventral margin of the head (data not shown).

We used live in vivo imaging with the sox10:EGFP transgene, which is expressed by CNC $[12,13]$, to learn whether the loss of expression of pdgfra was due to specific pdgfra down-regulation, or alternatively, to an absence of the CNC population normally migrating medial to the eye. Our findings strongly support the latter interpretation. By $16 \mathrm{hpf}, \mathrm{CNC}$ cells in control embryos migrate medial to the eye in a wedge-like pattern along the long axis of the eye, and toward the ventral and anterior margin of the eye (Figure 5B). However, in MO-injected embryos, few or no cells had migrated medial to the eye at $16 \mathrm{hpf}$ (Figure 5D). To test whether the reduction or absence of cells medial to the eye in MO-injected fish was due to delayed migration, embryos were imaged up to $18 \mathrm{hpf}$, and results showed no recovery of cell populations medial to the eye even at older stages (data not shown). Matching the pdgfra in situ results, we observed no changes in distribution of premigratory $\mathrm{CNC}$ expressing the transgene in MO-injected embryos and controls at $12 \mathrm{hpf}$ (data not shown), or at $14 \mathrm{hpf}$, when $\mathrm{CNC}$ cells first migrate medial to the eye (Figure 5A, C).

To quantify reduced or absent anterior-ward CNC cell migration and the specificity of this defect, we measured the maximum length of the migratory trajectories both medial to, and dorsal to the eye, as shown in Figure 5E. In both 14 and $16 \mathrm{hpf}$ embryos, the absolute distance from the posterior region of the eye to the frontier of neural crest cells medial to the eye in MO-injected fish was significantly shorter than in uninjected controls (Figure 5G, $p<0.001$ ). In 14 hpf embryos, the absolute distance to the frontier of neural crest cells dorsal to the eye was significantly longer in uninjected controls 

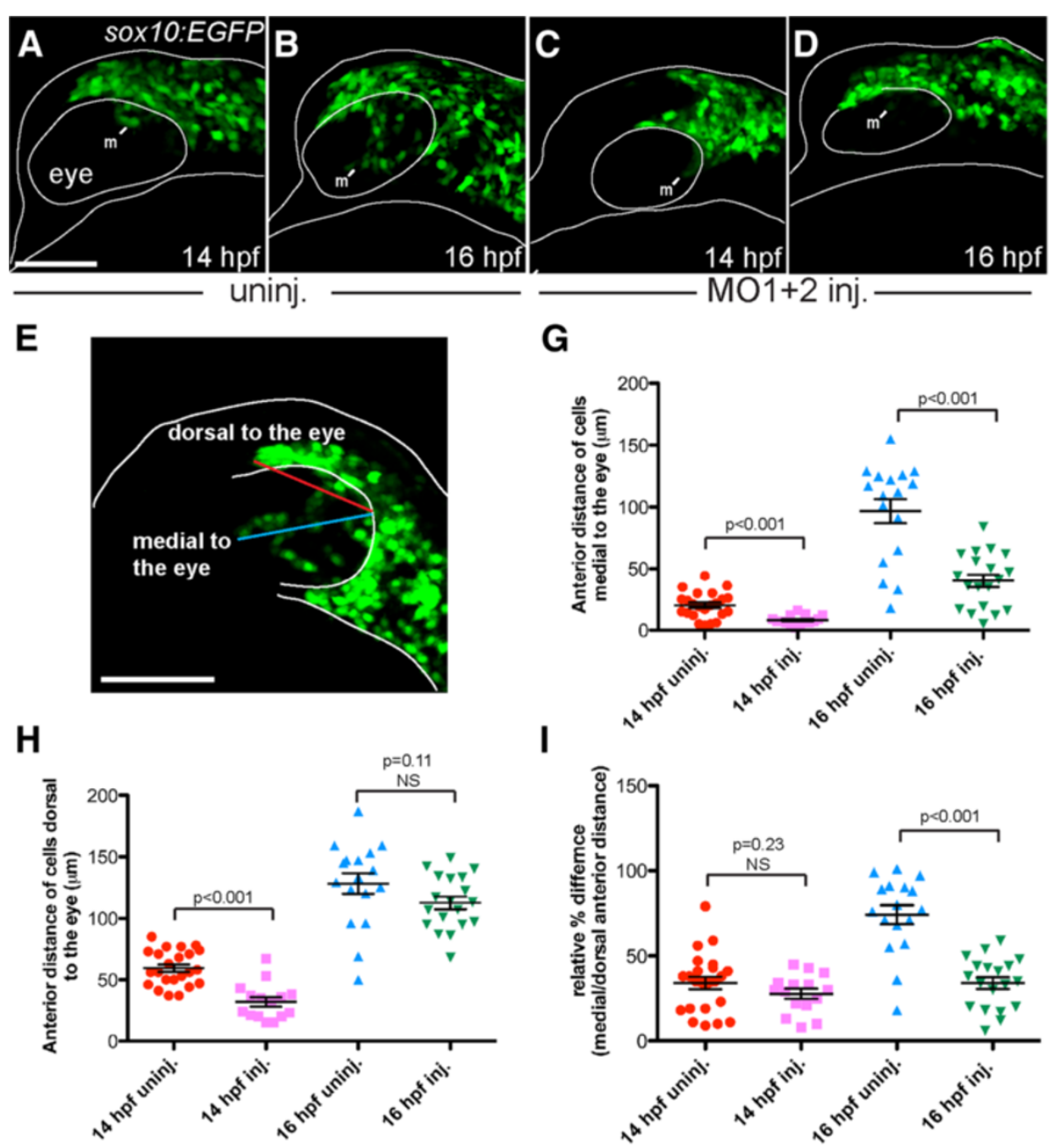

Figure 5 Migratory cranial neural crest cell populations medial to the eye are reduced in MO-injected embryos. (A-D) Live SOX10:EGFP transgenic embryos imaged at $14 \mathrm{hpf}(\mathbf{A}, \mathbf{C})$ and $16 \mathrm{hpf}(\mathbf{B}, \mathbf{D})$. (A-E) Lateral views: anterior is towards the left dorsal is upwards. (A and $\mathbf{B})$ Uninjected embryos $(n=6)$ showed migration of GFP-positive neural crest cells medial to the eye $(\mathrm{m})$ starting at $14 \mathrm{hpf}$. By $16 \mathrm{hpf}(\mathrm{B})$, cells migrated anteriorly and ventrally. (C and $\mathbf{D})$ hdac4 MO-injected embryos $(n=6)$ showed a reduction of GFP-positive cells medial to the eye $(m)$. (E) Measurement of the maximum length of the migratory trajectories of GFP-postive cells medial and dorsal to the eye (blue line and red line, respectively). Measurements were made on fixed uninjected and MO-injected sox10:EGFP transgenic embryos at 14 hpf (uninjected $n=23$, injected $n=15$ ) and $16 \mathrm{hpf}$ (uninjected $n=17$, injected $n=19$ ). $(\mathbf{G})$ The absolute distance from the posterior region of the eye to the frontier of GFP-positive cells medial to the eye in MO-injected fish was significantly shorter than in uninjected controls at both 14 and 16 hpf ( $p<0.001)$. $(\mathbf{H})$ The absolute distance to the frontier of GFP-positive cells dorsal to the eye was significantly longer in uninjected controls compared to the distance in MO-injected fish at $14 \mathrm{hpf}(p<0.001)$, but not at 16 hpf. (I) The relative percentage difference of medial vs. dorsal cell migration was not significant between MO-injected embryos and uninjected controls at $14 \mathrm{hpf}$, but becomes significant at $16 \mathrm{hpf}(p<0.001)$, indicating that while dorsal cell migration is not affected by MO-injection, medial cell migration is specifically affected. A-E: scale bar $=100 \mu \mathrm{m}$. G-I: error bars $=$ SEM. NS = not significant.

compared to the distance in MO-injected fish (Figure $5 \mathrm{H}$ ). However, at $16 \mathrm{hpf}$, there was no significant difference in the distance of cells dorsal to the eye between MOinjected embryos and uninjected controls, suggesting that by $16 \mathrm{hpf}$, the migration of cells dorsal to the eye in injected embryos is normal (Figure $5 \mathrm{H}$ ), whereas migration medial to the eye remained severely impaired. Such a specific defect is supported by comparing medial to the eye versus dorsal to the eye ratios: This normalized comparison of medial vs. dorsal cell migration was not significantly different when comparing MO-injected and uninjected embryos at $14 \mathrm{hpf}$ but became significant by 16 hpf (Figure 5I).

To address whether cell death may have caused reduction or absence of a particular subset of migratory cells we performed Acridine Orange (AO) staining of MOinjected and uninjected embryos at $14 \mathrm{hpf}(\mathrm{n}=5 \mathrm{MO}-$ injected, $\mathrm{n}=5$ uninjected) and $16 \mathrm{hpf}(\mathrm{n}=5 \mathrm{MO}$-injected, $\mathrm{n}=5$ uninjected). Compared with uninjected controls, MO-injected embryos did not show any localized increase 
in labeled degenerating cells in regions of the head populated by $\mathrm{CNC}$ cells fated to migrate medial to the eye and subsequently form the ethmoid plate (Additional file 4: Figure S4 and data not shown). We note that MO-injected embryos had overall higher levels of AO staining throughout the head compared to uninjected controls, likely due to non-specific effects of the morpholino.

\section{Reduction or absence of CNC cells in hdac4 MO-injected embryos explains the later palatal skeletal defects}

The population of cells in hdac-MO injected embryos that is reduced or absent is the same population of cells fate-mapped to generate the medial ethmoid plate $[12,13]$. Hence, no other later-acting role of hdac4 need be postulated to explain the ethmoid plate defects. Both the early and late phenotypes of reduced or missing CNC cells and palatal defects are variable, and if our interpretation is correct, then the severities of the early and late phenotypes should co-vary. To examine this prediction, we scored the hdac4 MO-induced disruption of post-migratory medial ethmoid progenitors located ventral and anterior to the eye, where they are associated with oral ectoderm [13,14] in live sox10:EGFP and fli1:EGFP transgenic embryos at $24 \mathrm{hpf}$, and then scored palatal skeletal defects in these same fish at 6 dpf (Figure 6A-F). We observed, as predicted, that in all cases $(\mathrm{n}=6 / 6$ sox10:EGFP embryos, $\mathrm{n}=9 / 9$ fli1:EGFP embryos) when GFP-positive cells condensing on the oral ectoderm were not detected at $24 \mathrm{hpf}$ (Figure 6C, E), cartilage defects were evident at $6 \mathrm{dpf}$ (Figure 6D, F). In cases where GFP-positive cells appeared to condense normally on the oral ectoderm at $24 \mathrm{hpf}$ in MO-injected embryos ( $n=2 / 2$ sox10:EGFP embryos), the palatal skeleton appeared normal at $6 \mathrm{dpf}$.

Examining a cross-sectional series of stages of palatal skeletal development of hdac4 MO-injected embryos expressing the $z c 81 \mathrm{Tg}$ transgene also supports our interpretation that missing CNC progenitor cells might explain the observed palatal defects (Figure 7). This transgene exquisitely and specifically labels the developing cartilages, beginning around $36 \mathrm{hpf}$ and continuing for days (Figure 7A-G). At each of the stages we examined, at $6 \mathrm{hr}$ intervals between $36 \mathrm{hpf}$ and about $60 \mathrm{hpf}$, the trabecular cartilages of MO-injected embryos appear reduced in size, consistent with being due to a secondary effect of missing early CNC precursor cells (Figure 7 $\mathrm{H}-\mathrm{L})$. Furthermore, beginning at about $60 \mathrm{hpf}$ the medial ethmoid region begins to fill in with labeled cells in uninjected controls (Figure 7E), but not completely in injected embryos (Figure 7L). Lack of cartilage at the medial ethmoid region is a feature that persists in $\mathrm{MO}$-injected embryos, resulting in holes or clefts in the ethmoid plate (Figure 7M, N).

\section{Discussion}

The palatal skeleton of the larval zebrafish is a useful model for studying genes involved in early palatogenesis in all vertebrates, including humans [14]. Here we provide evidence for a critical role of hdac4 in a migratory or premigratory anterior population of $\mathrm{CNC}$ cells, the cells that eventually generate the palatal skeleton. Reduction of hdac4 function results in embryos and larvae with shortened faces and skeletal reduction and/or clefting. Because loss of HDAC4 is associated with craniofacial defects that include oral clefts in humans $[9,10]$, understanding the role of Hdac4 function in zebrafish palatal skeleton development is likely relevant to understanding the function of HDAC4 in human palatal development. In particular, based on our findings in zebrafish, one could well suppose that very early perturbation of CNC development could also underlie the human palatal defects.

\section{Defects of the palatal skeletal cartilages in hdac4-MO injected embryos result secondarily from early disruption of migratory or premigratory CNC cells}

During normal development, the anteriorly-located CNC cells migrate in streams located posterior, medial, and dorsal to the eye, the medial cells eventually accumulating at the optic stalk at 20-24 hpf, before going on to form the medial region of the ethmoid plate, the skeletal region affected most in our hdac4 MO-injected embryos [12-14]. We find that at $16 \mathrm{hpf}$, hdac4 MO-injected embryos showed either a complete absence of, or significantly fewer, CNC cells migrating medial to the eye compared to uninjected controls. There is no evidence that the cells are present, and then disappear, and it remains unclear if cells are lacking in the pre-migratory $\mathrm{CNC}$ pool posterior to the eye, which includes other skeletal precursor cells (e.g., the trabecular precursors), or if cells simply fail to migrate. All subsequent cartilaginous defects likely result from the reduction or absence of this early population of progenitor cells: In 24 hpf hdac4 MO-injected fish, as expected from the early defect, post-migratory $\mathrm{CNC}$ cell populations were greatly reduced in the region of the anterior oral ectoderm, and by $6 \mathrm{dpf}$ these same fish displayed defects in the palatal skeleton itself.

In mouse, loss of Hdac4 causes no apparent loss of chondrocytes, but premature chondrocyte hypertrophy, resulting in early onset ossification of cartilage [11]. In zebrafish, we observe an early absence of specific CNC cells corresponding to a later loss of chondrocytes in the ethmoid plate region of the palate, strongly arguing that the origin of the defect in zebrafish is due to missing cells and not a defect in cartilage matrix production. Reduction or absence of post-migratory $\mathrm{CNC}$ cells in the anterior-most region of the forming palatal skeleton of 

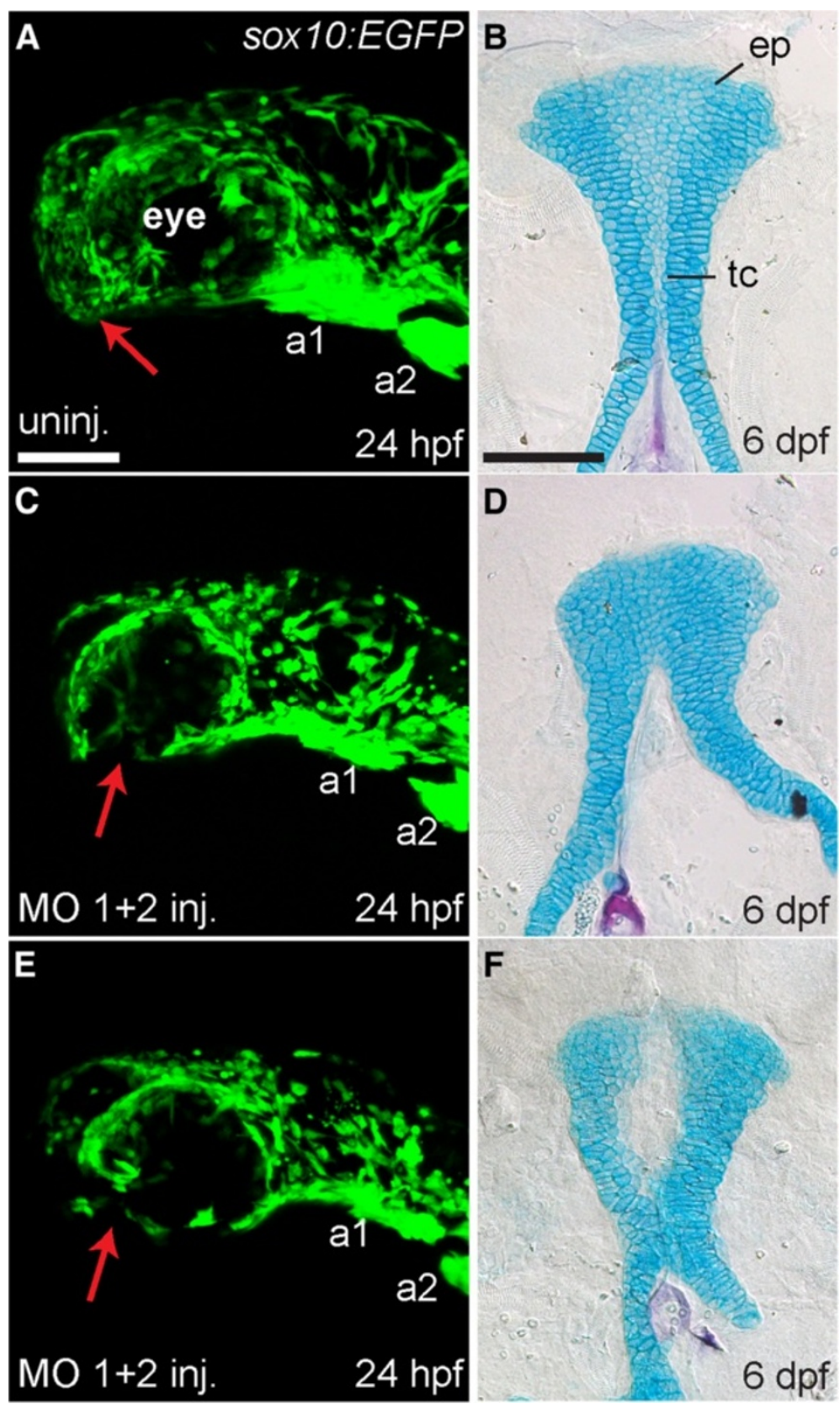

Figure 6 Reduction or absence of neural crest cells in MO-injected embryos is associated with palatal defects. (A,C,E) Lateral views of live sox 10:EGFP transgenic embryos at $24 \mathrm{hpf}$. Anterior is towards the left, dorsal is upwards. (B,D,F) Ventral view of Alcian Blue (cartilage) and Alizarin Red (bone) stained palatal skeletons of the same individual fish shown in $\mathbf{A}, \mathbf{C}, \mathbf{E}$, fixed and flat-mounted at $6 \mathrm{dpf}$. Anterior is upwards. (A) Uninjected embryos $(n=7)$ showed GFP expression in neural crest-derived tissues in the head including arch 1 (a1) and arch 2 (a2), and GFP-positive cells populate the anterior-ventral margin of the face where the palatal skeleton forms (indicated by red arrow). (B) Uninjected embryos had normal development of the ethmoid plate (ep) and trabeculae communis (tc) of the palatal skeletons. (C and E) hdac4 MO-injected embryos $(n=6)$ showed GFP expression in neural crest-derived tissues in the head, including arch 1 (a1) and arch 2 (a2), but a lack of cells in the anterior-ventral margin of the face at $24 \mathrm{hpf}$ (indicated by red arrows) (D and F) The same hdac4 MO-injected embryos in C and E had palatal skeleton defects at $6 \mathrm{dpf}(n=6 / 6)$, including defects in formation of the trabeculae communis (D), and ethmoid plate $(\mathbf{F})$. A,C,E scale bars $=100 \mu \mathrm{m}, \mathrm{B}, \mathrm{D}, \mathrm{F}$ scale bar $=100 \mu \mathrm{m}$. 


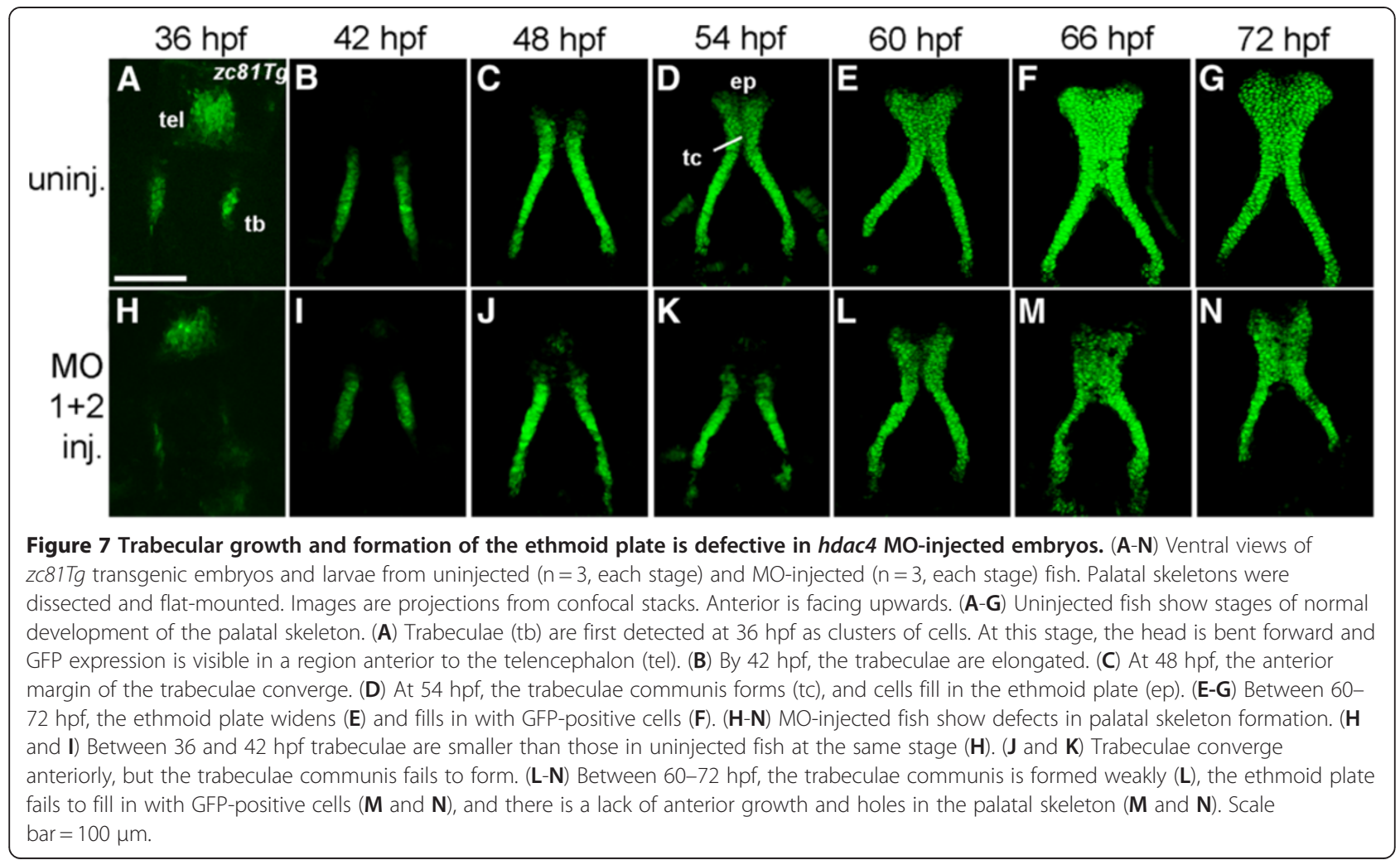

hdac4 MO-injected embryos at $24 \mathrm{hpf}$ is consistent with our proposal that the developmental defect occurs during the migratory or premigratory stages. We also observed hdac4 transcripts in the chondrocytes of the ethmoid plate (as well as other cartilages) at $72 \mathrm{hpf}$. The earlier requirement in the $\mathrm{CNC}$ itself, however, is sufficient to fully explain the palatal defects we observed. We also note that whereas the palatal defects are the most prominent ones observed, it is unlikely that this is the only deficiency. For example, MO-injected fish appear to have shorter faces overall, suggesting additional roles for Hdac4 in facial patterning.

Whereas we find that loss of hdac4 results in a CNC defect as early as $16 \mathrm{hpf}$, there are several possibilities as to what the exact defect(s) may be. As with loss of function of Pdgfra [14], the defect seems specific, or nearly so, for cells which normally migrate in a pathway medial to the eye. Hence one interpretation of our finding is these $\mathrm{CNC}$ cells lack the ability to recognize chemotactic or other cues that mark this pathway selectively. Alternatively, the defect could be further upstream, and result in the cell subset being improperly specified, or to be missing due to cell death. AO staining suggests that death of this specific migratory $\mathrm{CNC}$ cell population, or perhaps death of pre-migratory cells, is an unlikely mechanism causing the absence of cells.

Further work will be required to resolve this issue; at present critical markers labeling specific subsets of $\mathrm{CNC}$ cells are not available. The presence of some cells medial to the eye in our hdac4 MO-injected embryos suggests that $\mathrm{CNC}$ cells are capable of migrating correctly. However, their presence might well be due to the fact that our MOs do not knock down hdac4 completely. If so, then a model with complete loss of hdac4 function should result in absence of all CNC cells medial to the eye, and more severe palatal skeletal defects than we observed.

\section{Gene targets of Hdac4 involved in craniofacial development}

The gene targets of Hdac4 required in the $\mathrm{CNC}$ are unknown. Although established for $\mathrm{CNC}$ cell migration in the formation of the palatal skeleton [14], based on the results of this analysis, pdgfra and pdgfaa are not direct transcriptional targets of Hdac4 repression. Future investigation, by transcriptional screening or protein co-immunoprecipitation may identify targets Hdac4 required for zebrafish palatal skeletal development. In particular, targets of CNC cell specification or migration would help elucidate the cause of the early $\mathrm{CNC}$ cell defect.

An established target of repression by Hdac4 is Mef2c [7,8]. Loss of Mef2c in mice does not appear to result in defects involving the palatal skeleton or palate [30,31], although mice with loss of a single copy of both Mef2c and the Distal-less patterning genes Dlx5/6 suffer cleft palate [31]. Although zebrafish mef2ca mutants have no 
palatal defects (unpublished results), research is currently underway to understand the relationship between Hdac4 and mef2c genes (duplicated in zebrafish), in combination with $d l x$ genes in craniofacial development. Loss of mef2ca and $d l x$ genes cause other defects to the craniofacial skeleton in zebrafish [32,33] although analysis of their combined loss on palatal patterning is unknown.

In zebrafish, over-expression of the inhibitory microRNA miR-140 results in palatal skeleton reduction [14]. $m i R-140$ has also been identified as a repressor of Hdac4 in mouse [34], although Eberhart et al. (2008) did not identify any $m i R-140$ binding sites in the 3 '-UTR of zebrafish hdac4. Recent studies have challenged conventional wisdom that microRNAs only bind to the 3'UTR of genes by showing that microRNAs can also function by binding to targets in the coding sequence of genes [35]. Although two potential targets for miR-140 were identified for hdac4, clearly, any mechanistic function of miR-140 inhibiting hdac4 requires experimental testing. If $m i R-140$ has an additional function to repress hdac4 independent of pdgfra repression, it is possible that splice-inhibiting MO-induced down-regulation of hdac4 mRNA by $\mathrm{MO}$ could result in less target for $m i R-140$, thus leading to the availability of excess of $m i R-140$ that could repress other target genes, leading to palatal skeleton defects.

Development of the palatal skeleton in zebrafish and the mammalian palate involves control of $\mathrm{CNC}$ cell migration and condensation by many of the same gene pathways, including the $p d g f$ and shh pathways [12-14]. We have demonstrated that Hdac4 is another important gene involved in the regulation of a subset of CNC cells that form the palatal skeleton in zebrafish. Further understanding of the mechanism of Hdac4 function, and analysis of targets of Hdac4 activity will generate a more complete model of how Hdac4 controls development of the palatal skeleton, and should further inform understanding of how loss of HDAC4 in humans causes craniofacial disorders.

\section{Conclusions}

Knockdown of Hdac4 by morpholino results in the reduction or absence of a specific population of migratory $\mathrm{CNC}$ cells in the zebrafish head that normally contribute to the formation of the anterior palatal skeleton. Reduction or absence of migratory cells, detected by $16 \mathrm{hpf}$, corresponds with a reduction in CNC-derived antero-ventral cells of the face by $24 \mathrm{hpf}$, and then reductions of ethmoid plate cartilage, evident as early as $54 \mathrm{hpf}$. By $6 \mathrm{dpf}$, the ethmoid plate is shortened, clefted or missing. The results of this study offer insights into the mechanism of how Hdac4 normally functions in regulating early $\mathrm{CNC}$ cell behavior in craniofacial skeletogenesis. Since defects in HDAC4 in humans are associated with cleft palate, understanding the function of this gene in the normal specification and migration of $\mathrm{CNC}$ cells may reveal how loss of HDAC4 causes craniofacial malformations.

\section{Methods}

Fish maintenance and transgenic zebrafish

Fish were raised, staged, and euthanized according to established protocols [36,37]. All procedures were approved by The Institutional Animal Care and Use Committee (IACUC) at the University of Oregon. AB-strain fish were used for wild-type analysis and for morpholino (MO) and mRNA injections. MO-injected embryos were stagematched with wild-type embryos by somite number or other developmental criteria [37]. The transgenic lines $\mathrm{Tg}$ $(-4.9 \text { sox 10:EGFP) })^{b a 2}$ and $\operatorname{Tg}(\text { fli1:EGFP })^{y 1}$ label neural crest cells $[13,38] . z c 81 \mathrm{Tg}$ is a cartilage-specific transgenic discovered while making the $\operatorname{Tg}(\text { foxp2-enhancerA:EGFP })^{z c 42}$ transgenic [39].

Identification and sequence analysis of hdac4 in zebrafish Zebrafish hdac4 cDNA sequence was previously published in NCBI [Genbank: NW_001879481]. We originally identified a partial genomic sequence of hdac4 by alignment of the zebrafish genomic sequence with fulllength hdac4 sequences of other vertebrate species using ensembl zv7 [Ensembl: ENDARG00000041204]. Using Ensembl BLAST, we identified 3,518 bp of zebrafish hdac4, but not the full-length gene sequence as reported for other species. To identify the $5^{\prime}$ end of the gene, we used 5' RACE (Rapid Amplification of cDNA Ends) to identify a further $486 \mathrm{bp}$ at the $5^{\prime}$ end of the gene including the start codon (GeneRacer, Invitrogen). Fulllength hdac4 located on chromosome 9 is identified in Ensembl zv8 and zv9 versions of the zebrafish genome sequence. Alignment of Hdac4 protein sequence in zebrafish with human HDAC4 was performed using SIM alignment software [40]. MicroInspector [25] software was used to identify potential targets for the microRNA miR-140 in hdac4.

\section{Morpholino and mRNA design and injections}

Gene Tools supplied morpholino oligonucleotides targeting hdac4. Two splice-inhibiting morpholino oligonucleotides were designed that targeted the junction of exon-9 to intron-9 (MO1: ATTTGTTATGCCAGCGA CTGACCTG) and exon-10 to intron-10 (MO2: AGA GCCACAGAGGAGCTGCTTTACC) (see Figure 2A). One or two-cell stage embryos were injected using approximately $3 \mathrm{nl}$ of morpholino solution. Co-injection of both $\mathrm{MOs}(\mathrm{MO} 1=12 \mathrm{mg} / \mathrm{ml}+\mathrm{MO} 2=2 \mathrm{mg} / \mathrm{ml})$ was much more effective at knocking down mRNA splicing 
than either MO singly (see Figure 2B). Morpholinos were tested at a range of concentrations. The final concentration of the combined MO1 + MO2 dose gave the maximum penetrance of phenotypes with minimal lethality. A third splice-inhibiting MO targeting the junction of exon2 with intron-2 (MO3: AATCCCAGCAGCCTCACCTT GACAT), and a translation-inhibiting $\mathrm{MO}$ targeting exon-1 (MOTB: AGCGCCACACTCACATCAACCATC A) were also tested. A standard control $\mathrm{MO}$ provided by Gene Tools (CCTCTTACCTCAGTTACAATTTATA) was injected in parallel with injection of hdac4-targetting MOs, and hdac4 MO-like phenotypes were not observed in control-injected larvae.

Full-length cDNA of zebrafish hdac4 cloned into pBluescript KS + (Invitrogen) provided template for making sense mRNA for over-expression and rescue experiments. mRNA was synthesized using the mMessenger mMachine SP6 kit (Ambion) according to the manufacturer's protocol. For over-expression of hdac4 mRNA, $40 \mathrm{ng} / \mathrm{ul}$ of full-length hdac4 mRNA in a $3 \mathrm{nl}$ volume was injected into one-cell-stage embryos. For the rescue assay, hdac4 $\mathrm{MO} 1+2(12+2 \mathrm{mg} / \mathrm{ml})$ and hdac4 mRNA (20 ng/ul) was injected into one-cell stage embryos in a combined $3 \mathrm{nl}$ volume. For the rescue assay, doses of mRNA higher than $20 \mathrm{ng} / \mathrm{ul}$ resulted in early lethality when co-injected with the MOs.

\section{RT-PCR and immunodetection by Western blot}

Total RNA was extracted from whole embryos and larvae between $4 \mathrm{hpf}$ and 6dpf. 30 embryos/larvae at each stage were dissolved in $1 \mathrm{ml}$ Trizol (Invitrogen) and frozen at $-80^{\circ} \mathrm{C}$. mRNA was extracted according to the manufacturer's instructions and resuspended in $20 \mu \mathrm{l}$ of pure $\mathrm{H}_{2} \mathrm{O}$ with $0.5 \mu \mathrm{l}$ RNAse inhibitor (Roche). RT-PCR was performed using the Superscript III kit (Invitrogen) using OligoDTs according to the manufacturer's protocol. PCR was performed using standard protocols and reagents. The efficiency of splice-inhibition from MO1 was tested using primers designed to exon-8, exon-10 and intron-9. For $\mathrm{MO} 2$, primers were designed to exon-9, exon-11, and intron-10 (see Additional file 5: Figure S5).

For immunodetection by Western blotting, injected embryos and uninjected controls were harvested at 24 hpf and $6 \mathrm{dpf}$. At $24 \mathrm{hpf}, 30$ anesthetized embryos were de-chorionated and pooled together in $100 \mu \mathrm{L}$ SDS loading buffer $(0.63 \% 1 \mathrm{M}$ Tris- $\mathrm{HCl}, \mathrm{pH} 6.8,1 \%$ glycerol, $0.5 \%$ beta-mercaptoethanol, 35\% SDS). At 6dpf, 30 anesthetized embryos were pooled in $200 \mu \mathrm{L}$ SDS buffer. Embryos were boiled for $5 \mathrm{~min}$. and stored at $-80^{\circ} \mathrm{C}$ until use. Twenty micrograms of each protein was separated by SDS-PAGE and immunodetected using a polyclonal antibody raised against amino acids 530-631 of human HDAC4 (H-92, sc-11418, Santa Cruz Biotechnology). Proteins from SDS-PAGE gels were transferred to Immobilon $\mathrm{P}$ membrane (Millipore), and membranes were blocked by incubation with $4 \%$ non-fat dry milk in Tris-buffered saline (TBS) at $4^{\circ} \mathrm{C}$ overnight. The blot was then incubated in $4 \%$ non-fat dry milk in TBS, $0.05 \%$ Tween 20 (TBST) containing HDAC4 antibody. Goat anti-rabbit HRP-conjugated antibody was used as a secondary antibody (Pierce). ECL plus Western blotting Detection System (Amersham Biosciences) and X-OMAT AR film (Eastman Kodak Company) were used to detect signal.

\section{Tissue labeling and mounting}

Fixed 6dpf larvae were double stained using Alcian Blue (cartilage) and Alizarin Red (bone) using published protocols [41]. Palatal skeletons stained with Alcian Blue and Alizarin Red and palatal skeletons from transgenic animals were dissected and flat mounted as described [42]. We performed whole-mount fluorescent mRNA in situ hybridization as described [33], using previously described probes: hdac4 [43], pdgfra [14], pdgfaa [14]. Whole-mount embryos and larvae were mounted intact using 3\% methylcellulose and $1.2 \%$ agarose on standard glass slides and coverslips. To identify cell death, embryos were incubated for $20 \mathrm{~min}$. in $5 \mu \mathrm{g} / \mathrm{ml}$ Acridine Orange (AO, Sigma) dissolved in embryo medium in the dark. Embryos were then washed three times in embryo medium and mounted in $0.5 \%$ agarose in tissue culture dishes with cover glass bottoms (World Precision Instruments).

\section{Whole-mount and in vivo imaging}

For imaging both Alcian Blue and Alizarin Red stained samples and fluorescent transgenic palatal skeletons, palatal skeletons were dissected from the rest of the craniofacial skeleton and flat-mounted. For in vivo CNC cell migration studies sox10:EGFP transgenic embryos were mounted laterally on coverslips using 3\% methylcelluose and $1.2 \%$ agarose and sealed in chambers using vacuum grease. Embryos were staged according to somite number, and scanned by confocal microscopy approximately every 2 hours. Between scans, embryos were stored at $28.5^{\circ} \mathrm{C}$ in their sealed chambers.

\section{Image analysis and statistics}

Measurements were made on images using Zeiss AIM software. Statistics were performed using Excel (Microsoft) and Prism (GraphPad) software.

\section{Phylogenetic and conserved synteny analyses}

Phylogenetic and conserved synteny analysis was used to validate hdac4 orthology and to verify that it is present in single copy in the zebrafish genome [44-48]. A phylogenetic tree of vertebrate Hdac4 and outgroup (human HDAC5 and HDAC9) proteins was inferred using the Phylogeny.fr platform [49] including sequence alignment 
by MUSCLE [50], Maximum Likelihood phylogeny generation with PhyML (JTT + G + I model of protein evolution, 100 bootstrap replicates[51]) and tree drawing with TreeDyn [52]. Accession numbers are given in Additional file 1: Figure S1. Conserved synteny analyses were performed using the Synteny Database [53].

\section{Additional files}

Additional file 1: Figure S1. Protein alignment of human HDAC4 with zebrafish Hdac4. Functional domains are shaded as follows: CtBP-binding domain (pink), MITR-binding domain (yellow), serine residues associated with nuclear export by by chaperone 14-3-3 (blue), nuclear localization signal (grey), deacetylase domain (green), nuclear export signal (purple). Alignment was performed using SIM Alignment software.

Additional file 2: Figure S2. Maximum likelihood phylogeny of vertebrate Hdac4 proteins. Phylogenetic analysis of the single hdac4 gene in zebrafish showed that it is orthologous to one of the duplicated hdac4 sequences found in the genomes of several other teleosts, including medaka, stickleback and pufferfish. The tree is rooted with human HDAC5 and HDAC9 proteins encoded by genes paralogous to HDAC4 and along with $H D A C 7$, arising in the vertebrate $\mathrm{R} 1$ and $\mathrm{R} 2$ rounds of genome duplication. GenBank/ENSEMBL accession numbers are given for each sequence. Bootstrap values of 100 pseudoreplicates are shown; nodes with support below $50 \%$ have been collapsed. The position of the single zebrafish Hdac4 protein is ambiguous, but was assigned as an ortholog of the teleost Hdac4a proteins based on conserved synteny data (Additional file 3: Figure S3). Although the hdac4b gene is present in the medaka genome (scaffold279), its partial sequence was too short to be included in the phylogenetic reconstruction.

Additional file 3: Figure S3. Conserved synteny analyses of teleost hdac4 genes. Zebrafish hdac4 is adjacent to twist2 on linkage group 9. which reflects the location of human HDAC4 adjacent to TWIST2 The next most closely conserved sequence between zebrafish and human was an unannotated hdac7a-related pseudogene on linkage group 23 in zebrafish, adjacent to twist3. A) Dotplot of the zebrafish (Dre) hdac4 gene region on chromosome Dre9 ( $X$ axis) compared to the stickleback (Gac) genome ( $Y$ axis). The zebrafish hdac4 region shares extensive conserved synteny with the hdac $4 a$ region on stickleback chromosome groupXVI, but substantially less with the hdac4b region on groupl. Thus, the single hdac4 gene in zebrafish is hdac4a. B) Dotplot of the human (Hsa) HDAC4 gene on chromosome Hsa2 compared to the stickleback genome. The human HDAC4 regions shares extensive conserved synteny with both hdac4 regions in stickleback (groupXVI and groupl). The pufferfish and medaka genomes show a similar relationship (not shown), providing strong evidence for the generation of teleost hdac4 duplicates during the course of the teleost-specific genome duplication. (C) Dotplot of the human HDAC4 gene on Hsa2 compared to the zebrafish genome. Conserved synteny is shared with the hdac4a region on Dre9 as well as with Dre6 and Dre2. A second hdac4 gene, however, is not found on Dre6 nor on any other zebrafish chromosome suggesting that hdac4b has been lost in the zebrafish lineage. (D) Dotplot of the stickleback genomic region on linkage groupl (Gacgroupl) surrounding the $h d a c 4 b$ vs. the stickleback genomes (Dre chromosomes) showing that hdac4b in zebrafish was likely on Dre1 or Drfe6 before it was lost.

Additional file 4: Figure S4. Cell death is not increased in MOinjected embryos in regions where medially-migrating CNC cells are present. (A and B) Live embryos stained with $\mathrm{AO}$ and imaged at 14 hpf. Lateral views: anterior is towards the left dorsal is upwards. Images are projections from confocal stacks. MO-injected embryos had overall higher levels of AO staining throughout the head compared to uninjected controls. MO-injected embryos did not show any localized increase in labeled degenerating cells in regions of the head populated by CNC cells fated to migrate medial to the eye and subsequently form the ethmoid plate. Scale bar $=100 \mu \mathrm{m}$.

Additional file 5: Figure S5. hdac4 mRNA splicing is down-regulated in MO-injected embryos. RT-PCR of CDNA from whole embryo RNA extractions at $24 \mathrm{hpf}$ and $3 \mathrm{dpf}$. Combined injection of $\mathrm{MO} 1$ and $\mathrm{MO} 2$ resulted in down-regulation of normal splicing between exon-8 and exon-9 and exon-9 and exon-10 (e8e $10=$ PCR product showing splicing between exon-8 through exon-10 splicing; e9e11 = PCR product showing splicing between exon-9 through exon-11; e8i9 = PCR product showing mis-splicing resulting in inclusion of intron between exon-8 and intron-9; e9i10 $=$ PCR product showing mis-splicing resulting in inclusion of intron between exon-9 and intron-10). The expression of mRNA with intronic sequence was higher in injected embryos than in uninjected controls. RT-PCR for $\beta$-actin (control) was performed to demonstrate total mRNA levels used for RT-PCR were equal between samples.

\section{Competing interests}

The authors declare that they have no competing interests.

\section{Authors' contributions}

AD carried out morpholino injections, analysis of transgenics, skeletal preparations, molecular genetics studies, protein sequence analysis, and wrote the first draft of the manuscript. YN performed Western blot experiments. IB and JHP carried out phylogenetic and syntenic analyses. VK performed in situ hybridizations for pdgfra. HK and SW assisted YN with protein assays. CBK participated in the design, coordination and interpretation of experiments and helped to draft the manuscript. All authors read and approved the final manuscript.

\section{Acknowledgements}

We thank Johann Eberhart, Jared Coffin Talbot, Tom Titus, and Xinjun He for reagents and helpful discussions during the development of this project. We thank Bernard Thisse for the hdac4 in situ probe, and Joshua Bonkowsky for the $z c 81 \mathrm{Tg}$ transgenic line. We thank John Dowd and the UO fish facility for the care and maintenance of our fish. The authors are grateful to the University of Oregon zebrafish "groupie" attendees for helpful and friendly input. This work was funded by $\mathrm{NIH}$ grants HD022486 (to C. B. K. and J. H. P.), DE013834 (to C. B. K), DE020076 and RR020833 (to J. H. P.), grants from the Alexander von Humboldt Foundation and the Volkswagen Foundation (to I. B.), and IF32DE019345 (to A.D.).

\section{Author details}

'Institute of Neuroscience, 1254 University of Oregon, Eugene, OR 97403, USA. 'Department of Orthopaedic Surgery, Showa-Inan General Hospital, Akaho 3230, Komagane 399-4117, Japan. ${ }^{3}$ Department of Orthopaedic Surgery, Shinshu University School of Medicine, Asahi 3-1-1, Matsumoto 390-8621, Japan. ${ }^{4}$ Department of Health and Sports Sciences, Mukogawa Women's University, Nishinomiya 663-8137, Japan.

Received: 5 January 2012 Accepted: 30 April 2012

Published: 7 June 2012

\section{References}

1. Le Douarin NM: The Neural Crest. Cambridge: Cambridge University Press; 1982.

2. Noden DM: The role of the neural crest in patterning of avian cranial skeletal, connective, and muscle tissues. Dev Biol 1983, 96:144-165.

3. Gritli-Linde A: Molecular control of secondary palate development. Dev Biol 2007, 301:309-326

4. Mossey PA, Little J, Munger RG, Dixon MJ, Shaw WC: Cleft lip and palate. Lancet 2009, 374:1773-1785.

5. Haberland M, Montgomery RL, Olson EN: The many roles of histone deacetylases in development and physiology: implications for disease and therapy. Nat Rev Genet 2009, 10:32-42.

6. Grozinger CM, Hassig CA, Schreiber SL: Three proteins define a class of human histone deacetylases related to yeast Hda1p. Proc Natl Acad Sci U S A 1999, 96:4868-4873.

7. Wang AH, Bertos NR, Vezmar M, Pelletier N, Crosato M, Heng HH, Th'ng J, Han J, Yang XJ: HDAC4, a human histone deacetylase related to yeast HDA1, is a transcriptional corepressor. Mol Cell Biol 1999, 19:7816-7827. 
8. Miska EA, Karlsson C, Langley E, Nielsen SJ, Pines J, Kouzarides T: HDAC4 deacetylase associates with and represses the MEF2 transcription factor. EMBO J 1999, 18:5099-5107.

9. Park JW, Cai J, McIntosh I, Jabs EW, Fallin MD, Ingersoll R, Hetmanski JB, Vekemans M, Attie-Bitach T, Lovett M, et al: High throughput SNP and expression analyses of candidate genes for non-syndromic oral clefts J Med Genet 2006, 43:598-608.

10. Williams SR, Aldred MA, Der Kaloustian VM, Halal F, Gowans G, McLeod DR, Zondag S, Toriello HV, Magenis RE, Elsea SH: Haploinsufficiency of HDAC4 causes brachydactyly mental retardation syndrome, with brachydactyly type $\mathrm{E}$, developmental delays, and behavioral problems. Am J Hum Genet 2010, 87:219-228.

11. Vega RB, Matsuda K, Oh J, Barbosa AC, Yang X, Meadows E, McAnally J, Pomajzl C, Shelton JM, Richardson JA, et al: Histone deacetylase 4 controls chondrocyte hypertrophy during skeletogenesis. Cell 2004, 119:555-566.

12. Eberhart JK, Swartz ME, Crump JG, Kimmel CB: Early Hedgehog signaling from neural to oral epithelium organizes anterior craniofacial development. Development 2006, 133:1069-1077.

13. Wada N, Javidan Y, Nelson S, Carney TJ, Kelsh RN, Schilling TF: Hedgehog signaling is required for cranial neural crest morphogenesis and chondrogenesis at the midline in the zebrafish skull. Development 2005, 132:3977-3988.

14. Eberhart JK, He X, Swartz ME, Yan YL, Song H, Boling TC, Kunerth AK, Walker MB, Kimmel CB, Postlethwait JH: MicroRNA Mirn140 modulates Pdgf signaling during palatogenesis. Nat Genet 2008, 40:290-298.

15. Trainor PA, Melton KR, Manzanares M: Origins and plasticity of neural crest cells and their roles in jaw and craniofacial evolution. Int J Dev Biol 2003, 47:541-553.

16. Osumi-Yamashita N, Ninomiya Y, Doi H, Eto K: The contribution of both forebrain and midbrain crest cells to the mesenchyme in the frontonasal mass of mouse embryos. Dev Biol 1994, 164:409-419.

17. Schilling TF, Kimmel CB: Musculoskeletal patterning in the pharyngeal segments of the zebrafish embryo. Development 1997, 124:2945-2960.

18. Moore KL, Persaud TVN: The Developing Human: Clinically Oriented Embryology. 6th edition. Philadelphia: W.B. Saunders; 1998

19. Roessler E, Belloni E, Gaudenz K, Jay P, Berta P, Scherer SW, Tsui LC, Muenke M: Mutations in the human Sonic Hedgehog gene cause holoprosencephaly. Nat Genet 1996, 14:357-360

20. Tallquist MD, Soriano P: Cell autonomous requirement for PDGFRalpha in populations of cranial and cardiac neural crest cells. Development 2003, 130:507-518.

21. Li N, Felber K, Elks P, Croucher P, Roehl HH: Tracking gene expression during zebrafish osteoblast differentiation. Dev Dyn 2009, 238:459-466.

22. Wang $A H$, Yang $\mathrm{XJ}$ : Histone deacetylase 4 possesses intrinsic nuclear import and export signals. Mol Cell Biol 2001, 21:5992-6005.

23. Wang AH, Kruhlak MJ, Wu J, Bertos NR, Vezmar M, Posner BI, Bazett-Jones DP, Yang XJ: Regulation of histone deacetylase 4 by binding of 14-3-3 proteins. Mol Cell Biol 2000, 20:6904-6912

24. Fischle W, Dequiedt F, Hendzel MJ, Guenther MG, Lazar MA, Voelter W, Verdin E: Enzymatic activity associated with class II HDACs is dependent on a multiprotein complex containing HDAC3 and SMRT/N-CoR. Mol Cell 2002, 9:45-57.

25. Rusino $\vee$, Baev $\vee$, Minkov IN, Tabler M: Microlnspector: a web tool for detection of miRNA binding sites in an RNA sequence. Nucleic Acids Res 2005, 33:W696-W700.

26. Zhang CL, McKinsey TA, Lu JR, Olson EN: Association of COOH-terminalbinding protein (CtBP) and MEF2-interacting transcription repressor (MITR) contributes to transcriptional repression of the MEF2 transcription factor. J Biol Chem 2001, 276:35-39.

27. Heisenberg CP, Tada M, Rauch GJ, Saude L, Concha ML, Geisler R, Stemple $\mathrm{DL}$, Smith JC, Wilson SW: Silberblick/Wnt11 mediates convergent extension movements during zebrafish gastrulation. Nature 2000 405:76-81.

28. Dougan ST, Warga RM, Kane DA, Schier AF, Talbot WS: The role of the zebrafish nodal-related genes squint and cyclops in patterning of mesendoderm. Development 2003, 130:1837-1851.

29. Soriano P: The PDGF alpha receptor is required for neural crest cell development and for normal patterning of the somites. Development 1997, 124:2691-2700.

30. Arnold MA, Kim Y, Czubryt MP, Phan D, McAnally J, Qi X, Shelton JM Richardson JA, Bassel-Duby R, Olson EN: MEF2C transcription factor controls chondrocyte hypertrophy and bone development. Dev Cell 2007, 12:377-389.

31. Verzi MP, Agarwal P, Brown C, McCulley DJ, Schwarz JJ, Black BL: The transcription factor MEF2C is required for craniofacial development. Dev Cell 2007, 12:645-652.

32. Miller CT, Swartz ME, Khuu PA, Walker MB, Eberhart JK, Kimmel CB: mef2ca is required in cranial neural crest to effect Endothelin1 signaling in zebrafish. Dev Biol 2007, 308:144-157.

33. Talbot JC, Johnson SL, Kimmel CB: hand 2 and Dlx genes specify dorsal, intermediate and ventral domains within zebrafish pharyngeal arches. Development 2010, 137:2507-2517.

34. Tuddenham L, Wheeler G, Ntounia-Fousara S, Waters J, Hajihosseini MK, Clark I, Dalmay T: The cartilage specific microRNA-140 targets histone deacetylase 4 in mouse cells. FEBS Lett 2006, 580:4214-4217.

35. Fang Z, Rajewsky N: The impact of miRNA Target Sites in Coding Sequences and in 3'UTRs. PLoS One 2011, 6.

36. Westerfield M: The Zebrafish Book: A Guide for the Laboratory Use of Zebrafish (Brachydanio Rerio). 5th edition. Eugene: University of Oregon Press; 2007

37. Kimmel CB, Ballard WW, Kimmel SR, Ullmann B, Schilling TF: Stages of embryonic development of the zebrafish. Dev Dyn 1995, 203:253-310.

38. Lawson ND, Weinstein BM: In vivo imaging of embryonic vascular development using transgenic zebrafish. Dev Biol 2002, 248:307-318.

39. Bonkowsky JL, Wang X, Fujimoto E, Lee JE, Chien CB, Dorsky Rl: Domainspecific regulation of foxP2 CNS expression by lef1. BMC Dev Biol 2008, 8:103

40. ExPASy Bioinformatics Resource Portal. http://expasy.org/tools/sim-prot.html.

41. Walker $M B$, Kimmel CB: A two-color acid-free cartilage and bone stain for zebrafish larvae. Biotech Histochem 2007, 82:23-28.

42. Kimmel CB, Miller CT, Kruze G, Ullmann B, BreMiller RA, Larison KD, Snyder $\mathrm{HC}$ : The shaping of pharyngeal cartilages during early development of the zebrafish. Dev Biol 1998, 203:245-263.

43. Bertrand S, Thisse B, Tavares R, Sachs L, Chaumot A, Bardet PL, Escriva H, Duffraisse M, Marchand $O$, Safi $R$, et al: Unexpected novel relational links uncovered by extensive developmental profiling of nuclear receptor expression. PLoS Genet 2007, 3:e188.

44. Amores A, Force A, Yan YL, Joly L, Amemiya C, Fritz A, Ho RK, Langeland J, Prince $V$, Wang $Y L$, et al: Zebrafish hox clusters and vertebrate genome evolution. Science 1998, 282:1711-1714.

45. Postlethwait JH, Yan YL, Gates MA, Horne S, Amores A, Brownlie A Donovan A, Egan ES, Force A, Gong Z, et al: Vertebrate genome evolution and the zebrafish gene map. Nat Genet 1998, 18:345-349.

46. Postlethwait JH, Amores A, Yan G, Austin CA: Duplication of a portion of human chromosome 20q containing Topoisomerase (Top1) and Snail genes provides evidence on genome expansion and the radiation of teleost fish. In Aquatic Genomics: Steps Toward a Great Future. Edited by Shimizu TA N, Hirono I, Takashima F. Tokyo: Springer; 2002:20-31.

47. Taylor JS, Braasch I, Frickey T, Meyer A, Van de Peer Y: Genome duplication, a trait shared by 22000 species of ray-finned fish. Genome Res 2003, 13:382-390.

48. Jaillon O, Aury JM, Brunet F, Petit JL, Stange-Thomann N, Mauceli E, Bouneau L, Fischer C, Ozouf-Costaz C, Bernot A, et al: Genome duplication in the teleost fish Tetraodon nigroviridis reveals the early vertebrate proto-karyotype. Nature 2004, 431:946-957.

49. Dereeper A, Guignon V, Blanc G, Audic S, Buffet S, Chevenet F, Dufayard JF, Guindon S, Lefort $V$, Lescot $M$, et al: Phylogeny.fr: robust phylogenetic analysis for the non-specialist. Nucleic Acids Res 2008, 36:W465-W469.

50. Edgar RC: MUSCLE: multiple sequence alignment with high accuracy and high throughput. Nucleic Acids Res 2004, 32:1792-1797.

51. Guindon S, Gascuel O: A simple, fast, and accurate algorithm to estimate large phylogenies by maximum likelihood. Syst Biol 2003, 52:696-704.

52. Chevenet F, Brun C, Banuls AL, Jacq B, Christen R: TreeDyn: towards dynamic graphics and annotations for analyses of trees. BMC Bioinforma 2006, 7:439.

53. Catchen JM, Conery JS, Postlethwait JH: Automated identification of conserved synteny after whole-genome duplication. Genome Res 2009 19:1497-1505.

doi:10.1186/1471-213X-12-16

Cite this article as: DeLaurier et al: Histone deacetylase-4 is required during early cranial neural crest development for generation of the zebrafish palatal skeleton. BMC Developmental Biology 2012 12:16. 